\title{
Effects of tail length on an escape maneuver of the Red-billed Streamertail
}

\author{
Christopher James Clark
}

Received: 28 April 2009/Revised: 27 October 2009/Accepted: 15 June 2010/Published online: 10 November 2010

(C) The Author(s) 2010. This article is published with open access at Springerlink.com

\begin{abstract}
Sexually selected, elongated tails in birds may impair or alter naturally selected functions related to flight. The aim of this study was to test whether experimental manipulation of tail length affected the kinematics of a low-speed escape maneuver. The Red-billed Streamertail (Trochilus polytmus) has the longest tail of any hummingbird and is highly sexually dimorphic in tail length. I hypothesized that streamertails with either a long tail or with the tail removed would perform maneuvers with reduced linear and angular accelerations, relative to maneuvers performed with a short tail. Two high-speed video cameras recorded maneuvers from male and female Red-billed Streamertails under three tail length treatments: short tail, long tail, and no tail. The detailed kinematics of the maneuvers were highly variable. Whereas the birds always performed rolls (rotation about the bird's $X$-axis) during the maneuver, there was variation in the relative importance of pitching motions (rotation about the $Y$-axis) or yawing motions (rotation about the $Z$-axis), with yawing rotations playing a small role in 'pitch-roll' turns, and pitching motions playing a small role in 'yaw/roll' turns. Birds missing their entire tail exhibited reduced maximum linear accelerations associated with a curving trajectory. By contrast, birds maneuvering with an elongated tail did
\end{abstract}

Communicated by A. Hedenström.

\section{J. Clark}

Museum of Vertebrate Zoology, University of California, Berkeley, Berkeley, CA 94720, USA

\section{Present Address:}

C. J. Clark $(\bowtie)$

Peabody Museum of Natural History, PO Box 208106,

New Haven, CT 06520, USA

e-mail: christopher.clark@yale.edu not exhibit significantly different kinematics from the controls, suggesting that the greatly elongated tail streamers have relatively small effects on the bird's ability to maneuver at low speeds. Based on these observations, greatly elongated tails may not pose a large cost to lowspeed maneuvering flight.

Keywords High-speed video $\cdot$ Maneuver .

Red-billed Streamertail · Rotation · Tail .

Trochilus polytmus

\section{Introduction}

The elongated tails of numerous birds are a classic example of a sexually selected morphological trait (Andersson 1982, 1992; Petrie et al. 1991; Pryke and Andersson 2002). Birds also use their tails to produce aerodynamic forces in flight (Gatesy and Dial 1993; Maybury and Rayner 2001; Maybury et al. 2001; Tobalske 2007; Usherwood et al. 2005). Therefore, sexually selected modifications of tail morphology may impair or alter naturally selected functions related to flight.

Take, for example, high-speed forward flight, during which tail morphology has multiple influences on the drag generated by a bird's body. By studying a physical model of a Starling (Sternus vulgaris) in a wind tunnel, Maybury and Rayner (2001) showed that a short tail streamlines the body, reducing drag. Similarly, Clark and Dudley (2009) showed that attaching the elongated tail-streamers from the Red-billed Streamertail (Trochilus polytmus) to the Anna's Hummingbird (Calypte anna) resulted in an increase in the metabolic costs of flight and a decrease in the top speed the birds could fly, apparently caused by increased drag. These experiments show that an elongated tail can impair high- 
speed, linear flight. In the rapid flight studied in these hummingbird experiments, the birds held the tail shut and did not appear to use it to actively modulate aerodynamic force production.

A flight context in which the tail appears to be used to actively modulate force production is maneuvering flight (Hedrick and Biewener 2007; Warrick and Dial 1998). By spreading the tail widely to expose a relatively large surface area, birds generate aerodynamic forces (modeled by Maybury et al. 2001; Thomas 1993). Additionally, the mass of the rectrices causes the tail to have inertia. Together, aerodynamic forces and inertia will impart forces and torques that may influence the dynamics of maneuvers. Modified tail morphology may affect how birds maneuver by altering the forces that the tail produces.

It is unknown how forces generated by the tail may influence whole-animal maneuvering performance. This makes it difficult to use models of force production to predict how a maneuver would change with varying tail morphologies. An alternative approach to study how tail morphology influences flight is experimental manipulation of the tail of live birds, coupled with a measure of behavioral aspects of flight performance (Balmford et al. 2000; Clark and Dudley 2009; Evans et al. 1994; Rowe et al. 2001). One commonly used assay is a maze of strings: a released bird flies through the maze, and the number of strings hit and the time required to fly through the maze are measured (Balmford et al. 2000; Evans et al. 1994; Matyjasiak et al. 2004). Alternately, Matyjasiak et al. (1999, 2000) measured differences in foraging success of Sand Martins (Riparia riparia) as a function of different tail morphologies, and Evans and colleagues (Buchanan and Evans 2000; Rowe et al. 2001) filmed the curving flight of swallows approaching their nests. While these behavioral methods can at times link variation in tail morphology to performance with obvious fitness consequences, such as the ability to catch prey (Matyjasiak et al. 1999, 2000), they do not address the functional connection between tail morphology and performance.

An intermediate between models (physical and mathematical) and behavioral analyses is the detailed analysis of one particular flight context in which the tail is thought to generate important forces. The aim of this study was to examine the detailed kinematics of an escape maneuver as a function of tail length. The Red-billed Streamertail of Jamaica was selected as the study species because females of this species have tails of a normal length whereas males have a pair of greatly elongated tail-streamers that are the longest tail feathers of any hummingbird (Clark 2010), and because hummingbirds are an excellent system for the study of the mechanics of flight. An escape maneuver was selected because in other slow maneuvers, hummingbirds do not spread their tail, whereas they do spread it widely when startled. Moreover, escape maneuvers potentially approach the maximal flight performance that an individual is capable of attaining, whereas maneuvers performed without a startle stimulus may vary greatly according to the behavioral motivation of the individual.

There are a large number of kinematic variables that are potentially important to maneuvering flight. During a maneuver, the whole animal can translate the movement in three dimensions $(X, Y$, and $Z$ ), as well as rotate about the $X$ (roll), $Y$ (pitch), and $Z$ (yaw) axes (Dudley 2002; Hedrick and Biewener 2007; Warrick et al. 2002). A bird's ability to modulate these kinematic variables will be strongly influenced by its initial flight speed. Therefore, I elected to elicit startles from hovering birds (velocity $=0 \mathrm{~ms}^{-1}$ ). I hypothesized that, in slow maneuvers, the tail generates forces that help the bird to rotate and produce a curved trajectory. Because at low speeds, an elongated tail may increase inertia and possibly drag, I hypothesized that an elongated tail would result in lowered linear accelerations and angular speeds attained over the course of the maneuver. Moreover, because the forces produced by a short tail potentially assist the bird in maneuvering, I hypothesized that removal of the entire tail would reduce the angular speed and linear accelerations attained during the maneuver.

\section{Methods}

\section{Experiment}

The experiment was performed in the town of Section, Portland Parish, Jamaica $\left(18^{\circ} 05.400^{\prime} \mathrm{N}, 076^{\circ} 41.940^{\prime} \mathrm{W}\right.$, approximately 1,000 m a.s.l.), in June-August of 2004 and 2005. Red-billed Streamertail (Trochilus polytmus) individuals were captured using mist nets during the annual molt. Birds that were missing any rectrices (tail-feathers) were not used for the study, but some individuals that were missing wing-feathers were included (none lost any additional wing feathers over the course of the experiment). After habituation to captivity, the birds were individually introduced into a 'flight arena' measuring $2.5 \times 2.5 \times 1.5 \mathrm{~m}$ (length $\times$ height $x$ width; Fig. 1). One end of the arena was arrayed with several perches, and this end was also near a natural light source to which the streamertails were attracted. As a result, the birds spent most of their time perched at this end of the flight arena. At the opposite end of the arena, a single feeder was provided from which the birds obtained food (Fig. 1). The feeder was suspended approximately $20 \mathrm{~cm}$ from the top of the arena. The sides of the arena were covered with plastic mesh (mesh size: $12 \times 12 \mathrm{~mm}$ ). The maneuver was filmed through this barrier. A white sheet was suspended from the top of the arena which constrained the area where the maneuver was filmed to $0.5 \mathrm{~m}$ in width (Fig. 1). 

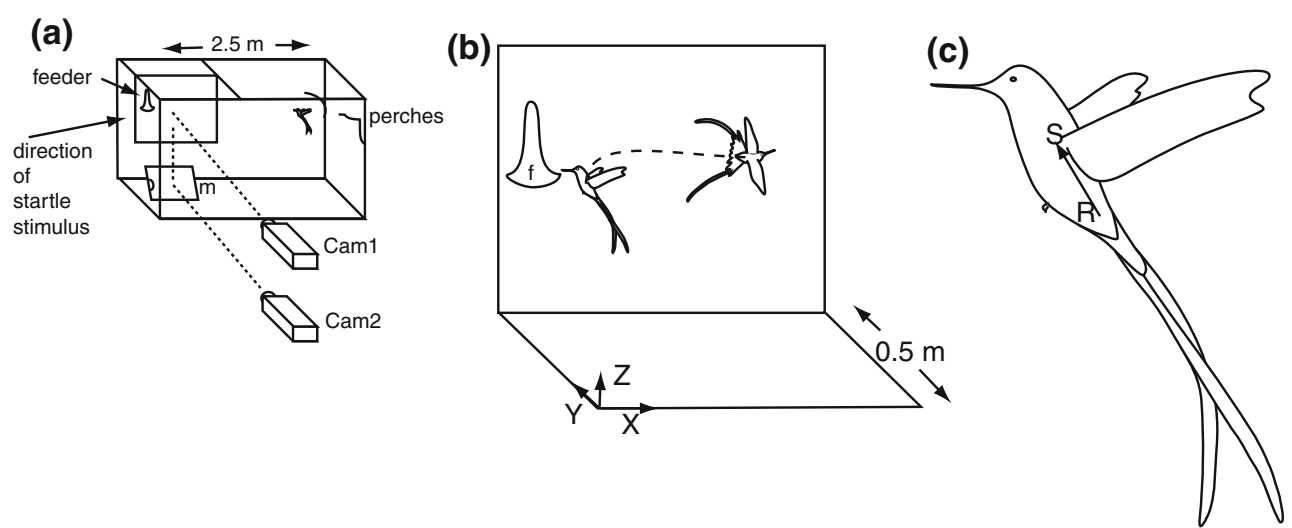

Fig. 1 The experimental setup for eliciting maneuvers from Redbilled Streamertail (Trochilus polytmus). a Flight arena $(2.5 \times 2.5 \times$ $1.5 \mathrm{~m}$, length $\times$ height $\times$ width). Perches were placed next to a natural light source at one end of the arena, and a feeder was placed in a $0.5-\mathrm{m}$-wide alcove at the other end of the arena. Two 500-W halogen lights (not shown) illuminated the feeder, and the space by the feeder was filmed with two high-speed cameras. One camera (Cam 1) obtained a side view, whereas the other camera (Cam 2) obtained a view from below through the use of a mirror $(m)$. b As a bird hovered at the feeder $(f)$, a startle stimulus was suddenly

The purpose of this experiment was to elicit behaviors from a hovering bird that were near to 'maximal' turning and linear accelerational performance. To elicit a turn of nominally $180^{\circ}$, the birds were startled as they hovered at or close to the feeder. Due to the shape of the arena, to escape, the birds had to turn around in order to linearly accelerate away from the feeder (Fig. 1).

Multiple stimuli to elicit the maneuver were tested; the birds exhibited the strongest response to large objects that suddenly, rapidly accelerated directly towards them. Use of a mechanical scare in which the experimenter was out-of-sight did not work well because the birds tended to flee in a random direction. The startle stimulus that resulted in the most consistent and repeatable flight trajectories (both within and between birds) entailed the experimenter standing as still as possible, in plain sight, approximately $0.8 \mathrm{~m}$ behind the feeder, outside of the flight arena. This meant that as a bird approached the feeder, it could see a human standing near the feeder through the mesh wall of the arena. After a bird approached and hovered at the feeder, a bright red cloth (a handkerchief) was abruptly accelerated directly towards the bird. Effort was made to accelerate the cloth in as repeatable a fashion as possible, such that in all startles the cloth followed a similar trajectory. The cloth was not in danger of actually hitting the bird, for its rapid motion was arrested by the mesh side of the flight chamber. Because the birds tended to approach the feeder warily, it appeared that the visible presence of the human standing behind the feeder caused the birds establish a predetermined direction in which to escape. accelerated towards it, causing it to perform an escape maneuver in which it turned and flew towards the perches (dashed line). The coordinate system was arrayed such that the $X Y$ plane was horizontal, the $Z$-axis vertical, and the $X$-axis was parallel to the direction of the startle stimulus. c Two points, the $\operatorname{rump}(R)$ and the shoulder $(S)$, were digitized on the birds over the course of the maneuver. The body vector was defined as the vector pointing from the rump to the shoulder, which was used to calculate the bird's pitch $(Y)$, yaw $(Z)$, and angular speed

After a few preliminary startles, the birds tended to approach the feeder with increased wariness. Over the course of the experiment, the birds were observed to ensure that they did not discontinue visiting the feeder altogether (which risked depriving the bird of food), damage their wing-feathers, or show signs of being unduly stressed (e.g, as indicated by clinging to the mesh of the walls of the arena, rather than using the provided perches). In the rare cases in which any of these events occurred, the experiment was terminated prematurely.

\section{Manipulations}

Four experimental manipulations of tail morphology were utilized (Fig. 2). Males and females were put through complementary manipulations. The first treatment was nomanipulation: males retained their long tail, and females, a short tail. The second manipulation was the reverse of their respective natural tail-lengths: in males, the streamers were replaced with the fourth rectrices from a female, and females were given a pair of the elongated fourth rectrices from a male. In the third manipulation, which was a second control, the feathers from the second treatment were removed, and the individual's original tail-feathers were reattached, resulting in long-tailed males and short-tailed females. Finally, in the fourth treatment, all ten rectrices (but not the tail-coverts) were plucked.

To splice the feathers into the tail, a bird was restrained and the distal portions of the birds' fourth rectrices were cut at a point $10-20 \mathrm{~mm}$ from the base. An insect pin (diameter 0.10 or $0.15 \mathrm{~mm}$, length $6 \mathrm{~mm}$ ) was dipped in 


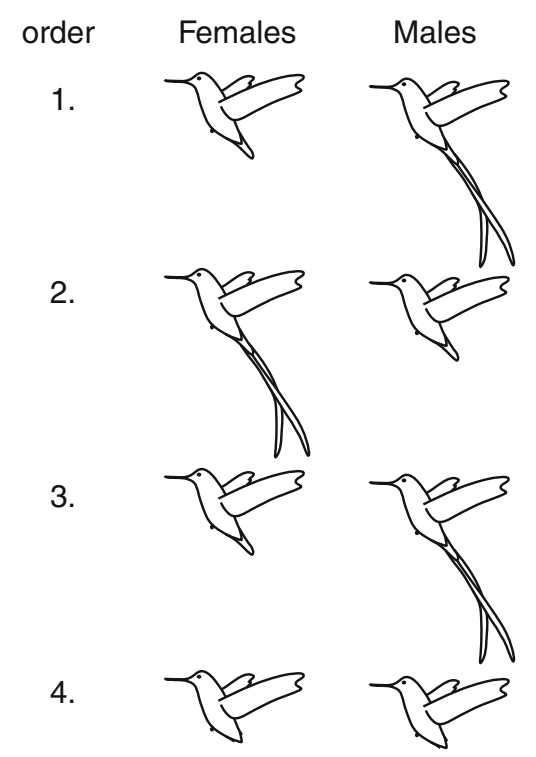

Fig. 2 Experimental manipulations used in this study. The elongated tail-feathers of male streamertails are the fourth rectrices, which is the second-to-outermost tail feather. 1 No manipulation, 2 tail morphology was manipulated, in which the fourth rectrices of males were spliced onto females, and visa versa, 3 an individual's original rectrices were spliced back on as a second control, 4 all of the rectrices were removed, rendering an individual with no tail

glue (cyanoacrylate) and inserted approximately $3 \mathrm{~mm}$ into the hollow shaft of the feather to be attached, such that the remaining $3 \mathrm{~mm}$ of the pin remained exposed. This free end was also dipped in glue and then inserted into the hollow shaft of the bird's fourth tail feather. The newly attached feather was positioned such that its vane was aligned with that of the bird's original feather (Fig. 1 in Clark and Dudley 2009). It was not possible to weigh the streamers used in the experiments, but a similar pair of streamers weighed approximately $0.02 \mathrm{~g}$, (Clark and Dudley 2009), which is approximately $0.4 \%$ of the Redbilled Streamertail's body mass.

The birds were startled during some of their repeated visits to the feeder, and each bird was startled consecutive times until at least three maneuvers had been obtained for each experimental treatment. To facilitate the comparison of maneuvers that were similar, a set of objective criteria were used to eliminate abnormal trials from consideration. For example, trials in which the bird sharply ascended or descended (resulting in significant changes in gravitational potential energy) were not used, nor were trials in which the bird flew backwards (rather than turning) or those in which the bird collided with the feeder or another part of the flight arena. Trials in which the bird slowed down (linearly decelerated) before it had traveled out of view of the cameras were also discarded. For a given bird, the data were usually obtained over the course of a single day but occasionally over two consecutive days.
On occasion, hummingbirds simultaneously lose their entire tail (i.e., all 10 rectrices) during molt (Stiles 1995) or when attacked by predators (Spofford 1976). Therefore, the manipulation of plucking all the tail-feathers falls within the natural range of variation of tail morphology naturally experienced by wild hummingbirds. Multiple subjects from these experiments were recaptured or observed in the wild to be behaving normally up to 3 weeks after release.

High-speed video analyses

The maneuvers were illuminated by two $500-\mathrm{W}$ halogen lights (V-light; Lowel, Hauppauge, NY) and recorded by two synchronized high-speed cameras (Redlake MotionMeter, $292 \times 210$ pixel resolution; Eastman Kodak,

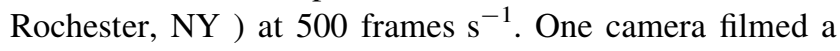
side view of the maneuver; the second camera obtained images from below, at $90^{\circ}$ to the first camera, through use of a mirror directly below the feeder (Fig. 1a).

The synchronized videos were digitized in the program Peak Motus ver. 8.4 (Vicon Motion Systems, Centennial, $\mathrm{CO})$. Two points were digitized on bird silhouettes in the videos: (1) the shoulder (S), which was a point internal to the bird's surface, between the wing bases, on the animal's midline, and close to the center of mass (Fig. 1c); (2) the rump (R), which was a point on the bird's dorsal surface, on its midline, and at the base of the tail, where the rectrices and tail-coverts insert into the body (Fig. 1c). Each point was digitized twice and averaged to reduce digitization error. External markers were not placed on the birds because both the birds' rotations and the wings inevitably occluded external markers for a significant period in all of the videos.

The object space for the trials was calibrated by digitizing the corners of a cube measuring $0.186 \times 0.136 \times 0.136 \mathrm{~m}$, which filled approximately $30-50 \%$ of the image of each camera. Using a Direct Linear Transformation in the program Peak Motus ver. 8.4, three-dimensional (3D) objectspace was established for each trial. The coordinate system was arrayed so that the $X-Y$ plane was horizontal and the $Z$-axis was vertical; the $X$-axis was oriented parallel to and away from the feeder and startle stimulus (Fig. 1b).

Linear velocities and accelerations of the shoulder point (which was close to the center of mass) were calculated. The shoulder and rump points were digitized from the silhouette, and it was impossible to digitize a third point on the bird's body. Because only the bird's body axis (as defined by the vector between the rump and shoulder points; Fig. 1c) was available, it was possible to calculate Euler angles corresponding to the body's pitch and yaw (Haslwanter 1995), but not roll. Because roll was unavailable, it was not possible to measure the angular velocity from these angles (Haslwanter 1995). Instead, a scalar index of the bird's angular speed was calculated at each instant in 
time by measuring the angular displacement of the bird's body angle relative to the instant $(0.002 \mathrm{~s})$ preceding it. A scalar index of angular acceleration was computed from the derivative of the angular speed. As these scalars exclude rotational contributions from the roll, these computed values will at times underestimate the magnitude of the bird's true angular velocity and acceleration.

The linear and angular positions, velocities, and accelerations were calculated using a quintic spline in Peak Motus ver. 8.4. The parameter representing the error variance (Walker 1998; Woltring 1985) used to smooth the spline will affect the estimated accelerations, especially the angular accelerations. As the purpose of this study was to compare different experimental manipulations to each other, I used the same error variance for all trials across all birds. Peak Motus's default method tended to underestimate the error variance, as determined by digitizing an object known to be accelerating under the force of gravity. Consequently, I selected an appropriate error variance by varying this parameter over three orders of magnitude and examining the fit between the spline and the raw data, for three randomly selected trials. The value $0.00008 \mathrm{~m}^{2}$ was selected because it resulted in the best average fit for the velocity data. Use of a different smoothing parameter would change the magnitude of the linear and angular accelerations that are presented here, but as it would affect all trials similarly, it appeared unlikely that a different smoothing parameter would affect the statistical results presented.

\section{Kinematic variables}

It was not possible to determine precisely when the bird began to react to the startle stimulus; therefore, the start of each maneuver (time $=0$ ) was operationally defined as the instant in which the bird's linear velocity exceeded $0.20 \mathrm{~m} \mathrm{~s}^{-1}$. Seven additional variables were obtained from the trials: (1) the time (after the start of the maneuver) it took the bird to travel $20 \mathrm{~cm}$ (resultant distance); (2) the magnitude of the bird's maximal resultant linear acceleration (a scalar); (3) the time (after the start of the maneuver) of the maximal linear acceleration; (4) the time at which the bird spread its tail (excluded in the no-tail treatment); (5) the time (after the start of the maneuver) that it took the bird to rotate through $120^{\circ}$ in yaw; (6) the timing and (7) magnitude of the bird's maximal angular speed. Velocities and accelerations were not recorded from the final ten samples from a trace in order to avoid 'edge' effects of the spline.

Angular speed was log-transformed to achieve a normal distribution, and four variables (time to travel $20 \mathrm{~cm}$, maximum linear acceleration, time taken to yaw $120^{\circ}$, and log maximum angular speed) were placed into a principal components analysis (PCA), without respect to bird identity or experimental manipulation. Based on the PCA, PC1
Table 1 Factor loadings from a PCA of maneuvers, and the percentage of variation attributable to the first two principal components

\begin{tabular}{lcc}
\hline Factors/variation & PC1 & PC2 \\
\hline Variables in PCA & & \\
Time to travel $20 \mathrm{~cm}$ & 0.697 & -0.141 \\
Maximum linear acceleration & 0.064 & 0.731 \\
Time to yaw $120^{\circ}$ & 0.714 & 0.097 \\
Log (max. angular speed) & -0.027 & 0.660 \\
Percentage of variation & 35.5 & 29.6 \\
\hline
\end{tabular}

$P C A$ principal component analysis

loaded strongly on the time to travel $20 \mathrm{~cm}$ and the time to yaw $120^{\circ}$, and weakly on the other two variables (Table 1 ). PC2 loaded heavily on the bird's ability to accelerate (i.e., angular speed and linear acceleration). The purpose of this experiment was to measure the bird's 'maximal' performance, whereas multiple maneuvers had been obtained for each experimental treatment. Because PC2 was an overall index of the bird's ability to accelerate, the trial with the highest PC2 score for each bird $\times$ treatment combination was kept for statistical analysis, and the remaining trials were dropped from the analysis.

Each of the kinematic variables was individually analyzed using repeated measures analysis of variance (ANOVA), with experimental treatment as a factor, bird as the repeated measure, and sex as a cofactor. Because males and females underwent a different time-series of experimental treatments (Fig. 2), two analyses were run. First, the four trials per bird were analyzed with respect to their temporal order, and without respect to the tail length. This was to test for time-dependent effects, such as effects caused by learning. Second, for each bird, the slower trial of treatments 1 and 3 was discarded (based on PC2), and the data were analyzed across the three tail-length treatments in a repeated measures ANOVA, with sex as a cofactor and a sex $\times$ treatment interaction term. The interaction term was included expressly to test whether there was a difference between males and females in their response to the experimental treatments. This could hypothetically occur, for example, if there were behavioral responses to tail manipulations of abnormal length, such as if females had lowered performance with a long tail, whereas males had lowered performance with a short tail.

\section{Results}

Description of the maneuver

Seven male and ten female Red-billed Streamertails were subjected to the experiments, although one male and two 
females did not complete all four treatments. Overall, the maneuvers had several features in common. The birds initially hovered stationary while facing the feeder (yaw $=0^{\circ}$ ), with a pitch angle of roughly $50^{\circ}$, and usually held the tail completely shut. Upon being startled, they immediately spread their tails widely in $100 \%$ of the trials ( $n=52$; no-tail trials excluded), while simultaneously initiating a rapid body rotation with bilaterally asymmetric wingbeat kinematics. The time at which their velocity reached $0.20 \mathrm{~m} \mathrm{~s}^{-1}$ was highly correlated with the time at which they spread their tail, with the birds spreading their tails on average $13.7 \pm 0.17 \mathrm{~ms}$ before their velocity reached $0.20 \mathrm{~m} \mathrm{~s}^{-1}$ ( $n=129$ maneuvers). This appeared to be a reasonable operational definition of the start of the maneuver; the time of tail-spread itself could not be used because the tail was absent in the no-tail treatment.

Once the maneuver was initiated, the bulk of the rotation was completed within $0.1 \mathrm{~s}$ of the start of the maneuver. This rotation was accompanied with translation in the $+X$ direction directly away from the stimulus and often also translation in $Y$; trials with significant translation in $Z$ were discarded. By the time they had translated $0.20 \mathrm{~cm}$, the birds had linearly accelerated to $2.4 \pm 0.35 \mathrm{~m} \mathrm{~s}^{-1}$ ( $n=67$ trials) in $0.17 \pm 0.033 \mathrm{~s}$ after the 'start' of the maneuver. During this time, the tail was spread widely and was occasionally elevated or depressed relative to the body pitch angle.

Outside of these common features, the birds exhibited considerable variation in the exact kinematics used to perform the turn. A main aspect of this variation appeared to center on the relative role of pitch or yaw in the rotations of the birds, and there appeared to be continuous variation in the importance of pitch or yawing motions. I name the two extremes of this continuum as "pitch-roll" turns (the hyphen indicates the rotations are approximately sequential), and "yaw/roll" turns (in which the slash indicates the rotations about these axes are simultaneous). Two trials typifying the two extremes of the continuum are presented in Figs. 3 and 4 and explained below.

\section{Pitch-roll turns}

At one end of the continuum, the birds occasionally performed a 'pitch-roll' turn (Fig. 3). A bird initiated the maneuver by first rotating purely in pitch, nose-up (tracings 1-4 in Fig. 3c), until the shoulder point passed over the rump point (frame 3 in Fig. 3), so that the yaw orientation instantaneously jumped from 0 to $180^{\circ}$ (arrow in Fig. 3e), and the bird was nominally upside-down (tracing 4 of Fig. 3c). Second, the bird initiated a roll (tracings $4-8$ of Fig. 3c), until it was right-side up, while maintaining a yaw orientation of $180^{\circ}$. In an idealized form of this maneuver, the birds could restrict the motion to include solely pitch and roll, without rotation in yaw (Fig. 3e). In reality, the yaw angle tended to vary with time in all of the observed trials, indicating that either the birds initiated the rolling rotation while continuing the pitching rotation, or because the bird did yaw as a part of the maneuver, or both. Because roll was not quantified, it was not possible to quantitatively distinguish between these possibilities.

\section{Yaw/roll turns}

At the other end of the continuum were 'yaw/roll' turns (Fig. 4), which appear to be similar to the banked turns analyzed in previous studies of flying birds (Hedrick and Biewener 2007; Hedrick et al. 2009; Warrick et al. 1998). To perform this type of maneuver, the birds simultaneously rolled and yawed to one side (tracings 2-9 of Fig. 4c), resulting in smooth variation in the yaw angle through the course of the maneuver (Fig. 4e). In contrast to pitch-roll turns, it may be possible for the pitch angle to vary little through the course of yaw/roll turns (compare Figs. 4e-3e), although towards the end of the turn, the pitch angle typically declined as the bird accelerated horizontally.

The escape maneuvers tended to fall in between these two extreme alternatives of 'pitch-roll' and 'yaw/roll' turns, and there appeared to be continuous variation between the two. Because roll was not quantified, it was also not possible to quantify each trial's location on this continuum. The point of outlining this continuum is to illustrate that, from one maneuver to the next, the individual changes in pitch and yaw could vary greatly, with the bird nevertheless attaining high linear and angular velocities and accelerations in the course of executing a $180^{\circ}$ turn.

\section{Linear motions}

At the start of the maneuver, in addition to rotating, the birds simultaneously linearly accelerated, primarily in the $X$ and $Y$ axes (trials with significant motion in $\mathrm{Z}$ were not included in the analyses). The operationally defined start of the maneuver (speed $>0.20 \mathrm{~m} \mathrm{~s}^{-1}$ ) is indicated with a gray line in Figs. 3d, e and 4d, e.

In pitch-roll turns, linear accelerations rose while the bird initiated the pitching motion (Fig. 3d) and then peaked during the rolling motion, when the bird was oriented away from the startle stimulus. Notably, acceleration in $Y$ remained low throughout the maneuver. For example, note that in Fig. 3d, the trace depicting resultant speed almost completely occludes the line depicting $X$-velocity.

In yaw/roll turns, linear accelerations were initially low while the bird initiated the start of the rotation (Fig. 4d). $Y$-acceleration initially rose faster than $X$-acceleration (Fig. 4d), and the bird began translating in $Y$. As the yaw 
(a) Position (side view)
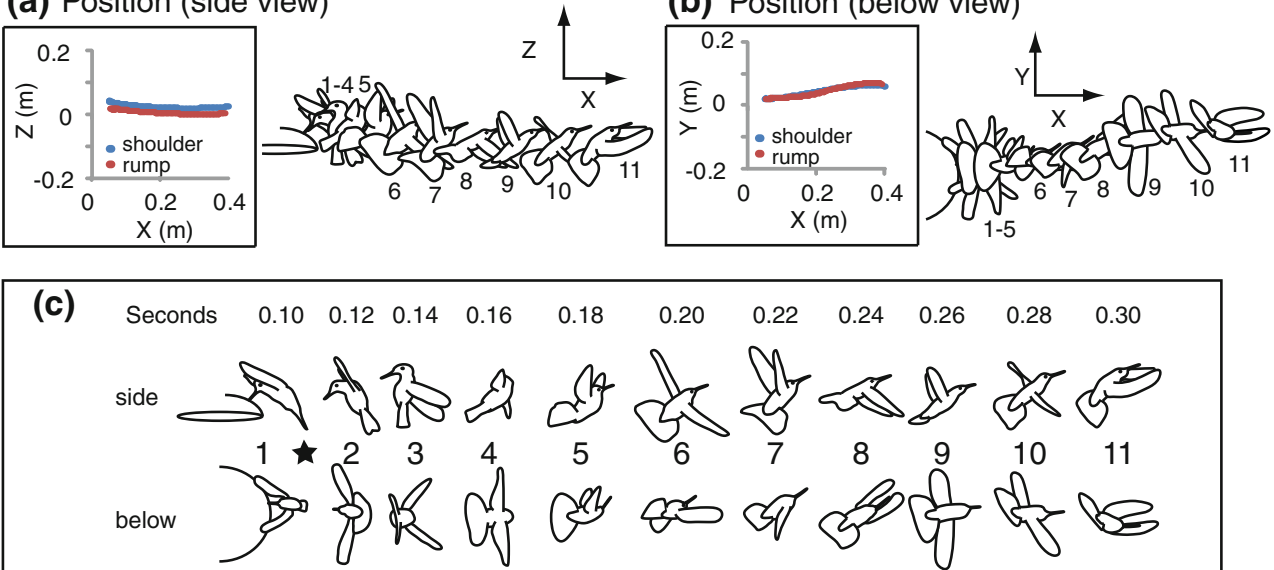

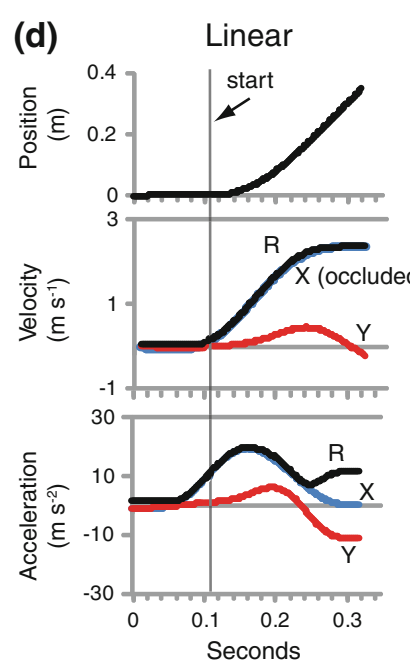

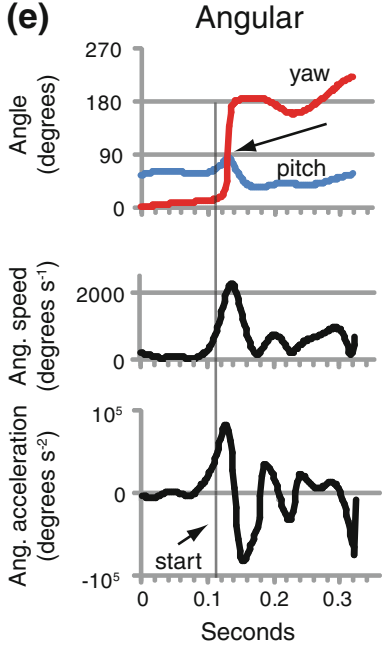

Fig. 3 A typical pitch-roll maneuver, performed by an unmanipulated female Red-billed Streamertail (which lacks elongated R4). Compare with Fig. 4. a Side perspective of the maneuvering hummingbird. Graph indicates the $X$ and $Z$ position of the shoulder and rump points. A series of 11 tracings (each $0.02 \mathrm{~s}$ apart) from the high-speed video are superimposed to reflect the actual position of the bird over time. b Perspective from below of the maneuvering hummingbird. Graph indicates the $X$ and $Y$ position of the shoulder and rump. Tracings matching those from (a) from a high-speed video are superimposed to reflect the actual position of the bird over time. c The same tracings as in (a) and (b) arrayed so that the body posture of the bird is visible. The 'start' of the maneuver (star) occurs between tracings 1 and 2. During the maneuver, the bird pitches noseup (tracings 2 and 3 ) followed by a roll (tracings 4-6). As a result, the bird executes an $180^{\circ}$ rotation in orientation with little translation in the $Y$ axis (b). d Linear kinematics of the shoulder point during the

angle passed through $90^{\circ}$ (Fig. 4e), the $X$-acceleration rose. The bird continued to rotate, and $X$-acceleration continued to rise as the yaw angle passed $90^{\circ}$ and approached $180^{\circ}$. As yaw approached $180^{\circ}$, the bird was both translating in $+X$ and $+Y$. To avoid colliding with the wall of the arena, the bird began to negatively accelerate in $Y$, while positive $X$ acceleration remained high. As a result, the maximum resultant linear acceleration in this type of maneuver pitch-roll maneuver, with motion in $X, Y$, and the resultant $(R)$. $Z$ components of motion (not shown) were small. The resultant velocity exceeded $0.2 \mathrm{~m} \mathrm{~s}^{-1}$ at time $=0.11 \mathrm{~s}$ (gray line $)$, which was operationally defined as the start of the maneuver. The $X$ velocity curve is almost entirely occluded by the resultant velocity. e Angular kinematics of the pitch-roll maneuver. Pitch and yaw have been calculated from the Euler angles of the body vector (see Fig. 1c). Angular speed and acceleration are both scalar values calculated from the scalar, angular change in body orientation in pitch and yaw. Angular velocities and accelerations (i.e., vectors) could not be calculated because roll data were unavailable. The start of the maneuver is indicated. Arrow indicates the instant in which pitch $\approx 90^{\circ}$, and yaw jumps from 0 to $180^{\circ}$. This occurs because the Euler convention has been used to define the body angles (Haslwanter 1995) and not because the bird has initiated a rotation in yaw (i.e., it has not begun to rotate about its own $Z$-axis)

tended to correspond to high positive $X$ acceleration and high $Y$ deceleration (Fig. 4d). Re-stated, the maximal acceleration was often associated with a curved portion of the bird's trajectory, in which the bird's acceleration corresponded to both to increases in speed and also changes in direction. This is in direct contrast to pitch-roll turns, in which resultant linear accelerations corresponded almost perfectly to linear $X$ acceleration (Fig. 3d), meaning that 
(a) Position (side view)

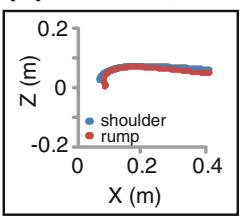

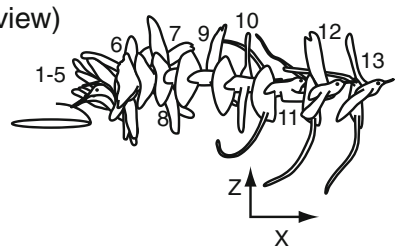

(b) Position (below view)
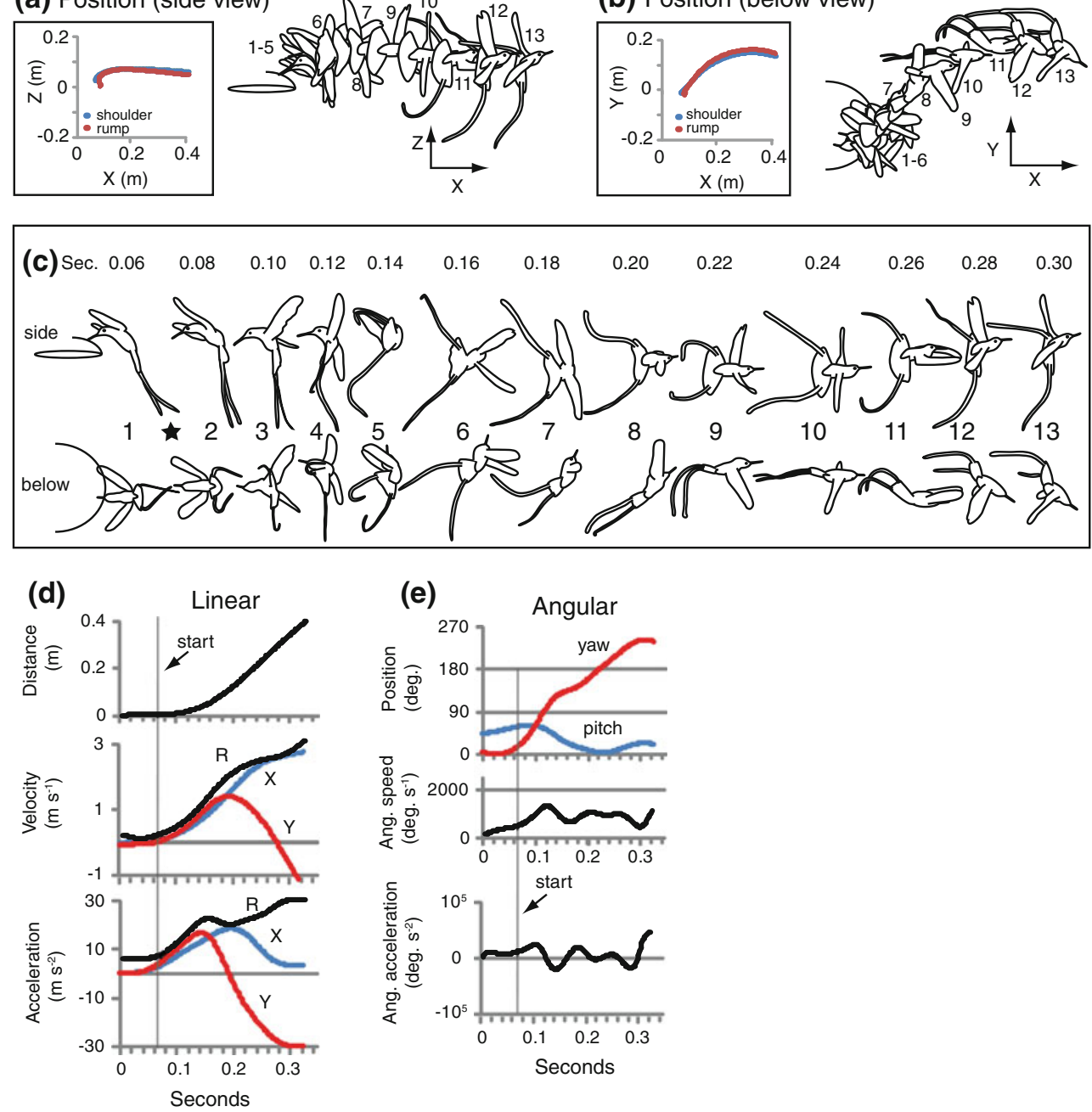

Fig. 4 A yaw/roll maneuver, performed by an unmanipulated male Red-billed Streamertail (with elongated 4th rectrices intact). Compare with Fig. 3; also note the dynamic bending of the tail streamers. a Side perspective of the maneuvering hummingbird. Graph indicates the $X$ and $Z$ position of the shoulder and rump points. A series of 13 tracings (each $0.02 \mathrm{~s}$ apart) from a high-speed video are superimposed to reflect the actual position of the bird over time. Tail-streamers have been omitted from tracings $1-10$ to improve clarity. b Bottom perspective of the maneuvering hummingbird. Graph indicates the $X$ and $Y$ position of the shoulder and rump. A series of 13 tracings match those from (a), superimposed to reflect the actual position of the bird over time (tail-streamers omitted from tracings 1-9). c The same 13 tracings as in (a) and (b) arrayed so that the body posture of the bird is visible. The 'start' of the maneuver (star) occurs between

the maximum acceleration corresponded primarily to changes in speed.

Notable differences between pitch-roll and yaw/roll turns

In addition to the differences in maximal linear acceleration just described, there were additional differences between the maneuvers depicted in Figs. 3 and 4. In the tracings one and two. During the maneuver the bird simultaneously yaws and rolls, which is especially evident in tracings 3-7. d Linear kinematics of the shoulder point during the yaw/roll maneuver, including $X, Y$, and resultant $(R) . Z$ components of motion (not shown) were small. The resultant velocity exceeded $0.2 \mathrm{~m} \mathrm{~s}^{-1}$ at time $=0.068 \mathrm{~s}$ (gray line $)$, which was operationally defined as the start of the maneuver. e Angular kinematics of the yaw/roll maneuver. Pitch and yaw have been calculated from the Euler angles of the body vector, where the body vector is the line between the shoulder and rump points (Fig. 1c). Angular speed and acceleration are both scalar values calculated from the scalar, angular change in body orientation in pitch and yaw. Angular velocities and accelerations (i.e., vectors) could not be calculated because roll data were unavailable. The start of the maneuver is indicated

pitch-roll turn (Fig. 3), there are two somewhat distinct rotations: first a pitching motion, followed by a roll. In the yaw/roll turns, rolling and yawing movements appear to be synchronized, such that they are difficult to distinguish. In pitch-roll turns, it is possible for the bird to exhibit a little translation in either the $Y$ or $Z$ dimensions (Fig. 3a, b) while turning completely around. By contrast, yaw/roll turns are characterized by distinct translation in $Y$, in addition to translation in $X$ (Fig. 4a, b). Because the birds 
had a choice in how to perform the maneuver, these differences resulted in substantial variation between individual maneuvers.

\section{Results of tail-length manipulations}

The PCA of the maneuvers is presented in Table 1. In the PCA, PC1 loaded highly on both the time taken to travel $20 \mathrm{~cm}$ and the time taken to yaw $120^{\circ}$, and little on maximum linear acceleration or log of maximum angular velocity. PC2 loaded highly on both maximum linear acceleration and $\log$ of maximum angular velocity. PC1 therefore was an index of how quickly the bird performed the maneuver, whereas PC2 represented a measure of the modulation of the linear and angular accelerations during the maneuver. Because the ability of a bird to muster linear accelerations (including the production of a curved trajectory) may be important components of a maneuver that could be affected by tail morphology, PC2 was used to select which trial represented a bird's 'maximal' performance.

Repeated measures ANOVAs of the maneuver variables with respect to the chronological order of the trials indicated that maximal linear acceleration exhibited significant variation between the chronological treatments $\left(F_{3,44}=\right.$ $7.98, P=0.0002)$. The individual treatment effects indicated that, of the four chronological treatments, the fourth treatment (which was also always the no-tail treatment) was significantly lower than the first, second, and third treatments $(t=-3.35, P=0.002)$, whereas the other three treatments were not significantly different (all $t<1.56, P>0.12$ ). Because there were no differences between the first three treatments, the statistical significance of the final treatment is interpreted as indicating that it is removal of the tail that reduces maximal linear acceleration, rather than it being due to a chronological effect. None of the other maneuver variables exhibited significant variation over the chronological order of treatments (all $F<1.91, P>0.14$ ).

The statistical analyses of the effects of tail length on the measured performance variables are presented in Table 2 . Of the variables considered, only the maximum linear acceleration varied with experimental treatment (repeated measures ANOVA, $n=51$ measures over 18 birds, $\left.F_{2,29}=21.9, P<0.0001\right)$; none of the other variables varied with experimental treatment (all $F<2.21$, $P>0.14)$. The statistical significance of maximum linear acceleration was driven by the significant difference between the short-tail treatment and the no-rectrices treatment $(t=-4.26, P<0.001)$, whereas the difference between the short-tail treatment and the long-tail treatment was not significant $(t=0.67, P=0.511)$. Moreover, there were no significant sex $\times$ treatment interactions for any of the variables (all $F<2.28, P>0.120$ ).
Because maximal linear acceleration was found to vary between experimental treatments, a post-hoc analysis of the maximal linear acceleration in $X$ and $Y$ was performed. A repeated measures ANOVA of the maximal $X$-acceleration indicated that the maximum $X$-acceleration was not significantly different between the experimental treatments $\left(n=51\right.$ measures over 18 birds, $\left.F_{2,29}=0.16, P=0.85\right)$, whereas the maximum $Y$-accelerations were significantly different between treatments $\left(F_{2,29}=4.22, P=0.025\right)$. As indicated in Fig. 4, maximum $Y$-acceleration was primarily associated with curving trajectories.

\section{Discussion}

The tail's role during maneuvers

Overall, the maneuvers performed by male and female Red-billed Streamertails were sufficient to rotate and rapidly propel the birds away from the startling stimulus. Because the tail (when present) was always widely spread at the onset of the maneuver, the kinematics suggest that the tail produced aerodynamic forces during the maneuver. This is supported by the finding that the bird's maximal linear accelerations were significantly reduced when the tail was removed. The point of maximal linear acceleration often coincided with the production of centripetal accelerations associated with a curving trajectory (i.e., changes in direction), suggesting that it was the ability to produce centripetal acceleration that was specifically reduced in tail-less birds. Consistent with this, the post-hoc analysis detected treatment differences in maximal $Y$-acceleration and not $X$-acceleration. In this experiment, high $Y$ decelerations occurred late in the yaw/roll turns (Fig. 4d), as the birds adjusted their trajectory to avoid colliding with the side of the flight arena. Therefore, it would appear that removing the tail from the Red-billed Streamertail decreased either the tendency or ability of the birds to change direction (i.e., produce a curved trajectory).

This reduction in maximal acceleration could be due to two effects. The birds may have adjusted the type of rotation performed to accommodate the absent tail, for example by shifting from tending to use yaw/roll turns, towards pitch-roll turns. This possibility does not seem to be wellsupported by the data, however; none of the other kinematic variables (such as angular speed) were statistically significantly different between the no-tail trails and the other trials, and a clear shift in the style of maneuver performed was not clearly evident in visual inspection of the videos.

The second possible explanation for the reduction in the maximal linear acceleration is that the birds utilized the widely spread tail to generate forces (aerodynamic and/or inertial) during the maneuver, and thus the bird's flight 
Table $2 F$ statistics from repeated measures ANOVAs examining the effects of tail length on maneuver performance $(n=51$ measures over 18 birds)

\begin{tabular}{|c|c|c|c|c|}
\hline Variable & Sex & Bird ID & Tail length & $\begin{array}{l}\text { Sex } \times \text { tail-length } \\
\text { interaction }\end{array}$ \\
\hline Time to travel $20 \mathrm{~cm}$ & $0.70(1)$ & $0.91(16)$ & $1.18(3)$ & $1.63(3)$ \\
\hline Maximum linear acceleration & $13.05^{*}(1)$ & $9.98 *(16)$ & $21.90 *(3)^{\mathrm{a}}$ & $1.53(3)$ \\
\hline Time of max. linear acceleration & $0.04(1)$ & $2.00(16)$ & $2.12(3)$ & $0.20(3)$ \\
\hline Time to yaw $120^{\circ}$ & $0.59(1)$ & $2.25(16)$ & $1.02(3)$ & $2.28(3)$ \\
\hline Log max. angular speed & $1.08(1)$ & $0.54(16)$ & $0.04(3)$ & $0.79(3)$ \\
\hline Time of max. angular speed & $0.01(1)$ & $1.27(16)$ & $0.66(3)$ & $0.73(3)$ \\
\hline $\mathrm{PC} 1$ & $0.65(1)$ & $1.46(16)$ & $1.00(3)$ & $2.14(3)$ \\
\hline $\mathrm{PC} 2$ & $6.14(1)$ & $1.41(16)$ & $3.18(3)^{\mathrm{b}}$ & $1.38(3)$ \\
\hline
\end{tabular}

Degrees of freedom are given in parentheses

ANOVA analysis of variance

${ }^{a}$ For maximum linear acceleration, the no-tail treatment (which was also always the last treatment) was significantly different from the short-tail and long-tail treatments $(t=-4.26, P=0.001)$, whereas short-tail and long-tail treatments were not significantly different $(t=0.67$, $P=0.511)$

b PC2 was marginally statistically significant across experimental treatments $(P=0.056)$; this result was driven by the no-tail treatment $(t=-$ $2.29, P=0.030)$ and not by differences between the long-tail and short-tail treatments $(t=-0.11, P=0.92)$. Notably, PC2 loaded highly on maximum linear acceleration (Table 1)

* $F$ values are statistically significant using a Bonferroni-corrected $P$ value of 0.006

performance was altered when missing the tail. Aerodynamic forces and torques produced by it could serve two functions. First, torques generated by the tail could serve to control pitching and/or yawing motions of the body. According to this hypothesis, when missing the tail, the bird would need to sacrifice some thrust from the wings to instead produce a functionally equivalent torque (if it did not do so, presumably it would lose control of flight). Second, the tail may simply function as an additional lifting surface, elevating the total average aerodynamic force the bird can produce (Thomas 1993). In the absence of a tail, the total aerodynamic force generated by the bird would be reduced.

Inspection of the high-speed videos tentatively suggested that the tail served to control pitching and/or yawing motions in the low-speed maneuvers investigated here. This is because the flight speed was low, which may preclude large aerodynamic forces generated by the tail. Also, in a small fraction $(<5 \%)$ of trials, the birds appeared to be unstable in pitch and/or yaw, as evidenced by strong oscillations in body pitch or yaw. A potential topic of future empirical research would be further investigation of these two potential functions of tail-generated forces.

\section{Effects of a long tail on maneuvers}

Whereas removing the entire tail resulted in a decrease in the maximum linear acceleration attained by the birds, no statistically significant differences between maneuvers with a short or long tail were detected. This suggests that the greatly elongated tail-streamers of the Red-billed Streamertail do not impose a significant flight cost to birds performing a lowspeed maneuver. This result differs from those of previous studies that have documented statistically significant differences in the flight of birds with different tail morphologies, including the Barn Swallow and martins (Matyjasiak et al. 2004; Rowe et al. 2001), cisticolas (Balmford et al. 2000), and the Red-billed Streamertail (Evans et al. 1994). One major difference between this study and these previous experiments is that the hummingbirds here were performing a low-speed maneuver (flying well under $4 \mathrm{~m} \mathrm{~s}^{-1}$ ), whereas in all of these previous studies, the birds flew at moderately high speeds, either through a maze (Evans et al. 1994), while approaching the nest (Park et al. 2000), or while foraging (Matyjasiak et al. 2004).

Aerodynamic forces scale as velocity squared (Norberg 1990), thus the forces developed by the tail will vary substantially with airspeed. Therefore, drag from the streamers may have been negligible, whereas this is not the case at high speeds (Clark and Dudley 2009). Consequently, elongated tail morphology may have relatively little influence on aerodynamic force production at low speeds.

Another possible effect on flight is the tail's contribution to the bird's inertia. I hypothesized that an elongated tail would reduce the magnitude of angular accelerations necessary to produce body rotation. However, there are three possible reasons why no effects of an elongated tail morphology on body rotations were detected. First, the measures of angular speed and acceleration presented here do not include contributions from roll, and it is possible that real differences in roll between the experimental treatments went 
un-measured. Second, the birds studied here exhibited high variability in maximal angular accelerations $[6.2 \pm 3.0 \times$ $10^{5 \circ} \mathrm{s}^{-2}$ ( $n \pm$ standard deviation); compare Fig. 3e with Fig. 4e], such that detecting statistically significant effects of tail morphology would necessitate either large sample sizes or pronounced experimental effects. Third, there are reasons to think that the effects of tail morphology on inertia would be subtle. For simplicity, previous estimates of the inertia by the tail have treated the tail as a stiff plate (Evans and Thomas 1992). However, the kinematics of the tail-streamers during the maneuver (Fig. 4) show that the streamers are extremely flexible and bend dynamically during the maneuvers. This bending may be widespread in long-tailed taxa, for it is qualitatively similar to the bending of Barn Swallow tailstreamers observed by Norberg (1994), and it would appear to decrease the effective moment of inertia; in this study, as a bird began to rotate, its streamers would bend, rather than imparting a large moment arm on the rotation. It seems likely that this effect reduces the effects a long tail may have on body rotations.

It is possible that small changes in flight performance present between the long- and short-tail treatments were rendered undetectable by the variation present in the kinematics of the maneuver. Flying organisms have six degrees of freedom of movement (three translational and three rotational; Dudley 2000) and can utilize multiple combinations of these degrees of freedom in the course of maneuvering. The maneuvers studied here were not stereotyped, as illustrated by the extremes depicted in Figs. 3 and 4. When rotating, the birds could incorporate either pitch, or alternately, yaw, without significant incorporation of the other type of rotation. This high degree of potential variation in kinematics would appear to benefit an animal performing an escape maneuver. For example, if an escape maneuver were stereotyped, it may be possible for predators or conspecifics to anticipate the target individual's trajectory, thereby impairing its utility as an escape tactic. Despite this variation, the experiment performed here produced significant differences between the maneuvers performed with and without a tail. Therefore, it would appear that if the tailstreamers impair flight, it is to a relatively small degree.

\section{Zusammenfassung}

Der Einfluss der Schwanzlänge auf ein Fluchtmanöver beim Wimpelschwanz

Sexuell selektierte, verlängerte Schwanzfedern bei Vögeln könnten natürlich selektierte Funktionen, die mit Flug in Zusammenhang stehen, behindern oder verändern. Das Ziel dieser Studie war $\mathrm{zu}$ testen, ob eine experimentelle Manipulation der Schwanzlänge die Kinematik eines langsamen Fluchtmanövers beeinflusst. Der Wimpelschwanz (Trochilus polytmus) hat den längsten Schwanz aller Kolibris und zeigt einen ausgeprägten Geschlechtsdimorphismus in der Schwanzlänge. Ich habe die Hypothese aufgestellt, dass Wimpelschwänze, die entweder einen langen Schwanz hatten oder deren Schwanz experimentell entfernt worden war, Manöver mit verminderten linearen und winkeligen Beschleunigungen vollführen, verglichen mit mit kurzem Schwanz ausgeführten Manövern. Zwei Hochgeschwindigkeits-Videokameras nahmen die Manöver männlicher und weiblicher Wimpelschwänze mit drei Schwanzlängen auf: kurzer Schwanz, langer Schwanz und kein Schwanz. Die detaillierte Kinematik der Manöver war höchst variabel. Während die Vögel bei den Manövern immer Rollbewegungen (Rotation um die x-Achse des Vogels) durchführten, variierte die relative Bedeutung von Neigungsbewegungen (Rotation um die y-Achse) oder Gierbewegungen (Rotation um die z-Achse). Gierungsrotationen spielten eine kleine Rolle bei „Neigungs-RollDrehungen" und Neigungsbewegungen eine kleine Rolle bei „Gier-Roll-Drehungen”. Vögel, denen der gesamte Schwanz fehlte, zeigten verminderte maximale lineare Beschleunigungen in Zusammenhang mit einer gekrümmten Bewegungsbahn. Im Gegensatz dazu zeigten Vögel, die mit einem verlängerten Schwanz manövrierten, keine signifikant unterschiedliche Kinematik verglichen mit Kontrolltieren, was darauf hindeutet, dass der stark verlängerte Schwanz der Wimpelschwänze relativ kleine Effekte auf die Fähigkeit des Vogels, bei geringer Geschwindigkeit zu manövrieren, hat. Stark verlängerte Schwänze dürften keine hohen Kosten bei langsamem Manövrierflug bedeuten.

Acknowledgments I am indebted to the assistance from Susan Koenig, Michael Schwartz, and the residents of the town of Section. Research and CITES export permits were granted by the National Environmental Protection Agency (NEPA) of Jamaica. Funding was generously provided by the American Ornithologist's Union, the MVZ, Sigma Xi, the Center for Latin American Studies, the AMNH, and the Department of Integrative Biology. I am indebted to Robert Dudley for use of his equipment. This manuscript was improved from comments provided by Robert Dudley, Jim McGuire, and Steve Beissinger. This project is a portion of my $\mathrm{PhD}$. dissertation. All protocols were approved by the UC Berkeley Animal Care and Use Committee.

Open Access This article is distributed under the terms of the Creative Commons Attribution Noncommercial License which permits any noncommercial use, distribution, and reproduction in any medium, provided the original author(s) and source are credited.

\section{References}

Andersson M (1982) Female choice selects for extreme tail length in a widowbird. Nature 299:818-820 
Andersson S (1992) Female preference for long tails in lekking Jackson's widowbirds: experimental evidence. Anim Behav 43:379-388

Balmford A, Lewis MJ, Brooke MDL, Thomas ALR, Johnson CN (2000) Experimental analyses of sexual and natural selection on short tails in a polygynous warbler. Proc R Soc Lond B 267:1121-1128

Buchanan KL, Evans MR (2000) The effect of tail streamer length on aerodynamic performance in the barn swallow. Behav Ecol $11: 228-238$

Clark CJ (2010) The evolution of tail shape in hummingbirds. Auk 127:44-56

Clark CJ, Dudley R (2009) Flight costs of long, sexually selected tails in hummingbirds. Proc R Soc Lond B 276:2109-2115

Dudley R (2000) The biomechanics of insect flight: form, function, evolution. Princeton University Press, Princeton

Dudley R (2002) Mechanisms and implications of animal flight maneuverability. Int Comp Biol 42:135-140

Evans MR, Thomas ALR (1992) The aerodynamic and mechanical effects of elongated tails in the scarlet-tufted malachite sunbird: measuring the cost of a handicap. Anim Behav 43:337-347

Evans MR, Martins TLF, Haley M (1994) The asymmetrical cost of tail elongation in red-billed streamertails. Proc R Soc Lond B 256:97-103

Gatesy SM, Dial KP (1993) Tail muscle activity patterns in walking and flying pigeons (Columba livia). J Exp Biol 176:55-76

Haslwanter T (1995) Mathematics of three-dimensional eye rotations. Vis Res 35:1727-1739

Hedrick TL, Biewener AA (2007) Low speed maneuvering flight of the rose-breasted cockatoo (Eolophus roseicapillus). I. Kinematic and neuromuscular control of turning. J Exp Biol 210: $1897-1911$

Hedrick TL, Cheng B, Deng X (2009) Wingbeat time and the scaling of passive rotational damping in flapping flight. Science 324:252-255

Matyjasiak P, Jabłoński PG, Olejniczak I, Boniecki P, Lee S-D (1999) Foraging cost of a long tail ornament: an experiment with sand martin females. Ethology 105:521-530

Matyjasiak P, Jabłoński PG, Olejniczak I, Boniecki P (2000) Imitating the initial evolutionary stage of a tail ornament. Evolution 54:704-711

Matyjasiak P, Matyjasiak J, de Lope F, Møller AP (2004) Vane emargination of outer tail feathers improves flight manoeuvrability in streamerless hirundines, Hirundinidae. Proc R Soc Lond B 271:1831-1838

Maybury WJ, Rayner JMV (2001) The avian tail reduces body parasite drag by controlling flow separation and vortex shedding. Proc R Soc Lond B 268:1405-1410
Maybury WJ, Rayner JMV, Couldrick LB (2001) Lift generation by the avian tail. Proc R Soc Lond B 268:1443-1448

Norberg U (1990) Vertebrate flight. Springer, Berlin

Norberg RA (1994) Swallow tail streamer is a mechanical device for self-deflection of tail leading edge, enhancing aerodynamic efficiency and flight manoeuvrability. Proc R Soc Lond B 257:227-233

Park KJ, Evans MR, Buchanan KL (2000) Assessing the aerodynamic effects of tail elongations in the house martin (Delichon urbica): implications for the initial selection pressures in hirundines. Behav Ecol Sociobiol 48:364-372

Petrie M, Halliday T, Sanders C (1991) Peahens prefer peacocks with elaborate trains. Anim Behav 41:323-331

Pryke SR, Andersson S (2002) A generalized female bias for long tails in a short-tailed widowbird. Proc $\mathrm{R}$ Soc Lond B 269:2141-2146

Rowe LV, Evans MR, Buchanan KL (2001) The function and evolution of the tail streamer in hirundines. Behav Ecol $12: 157-163$

Spofford SH (1976) Roadrunner catches hummingbird in flight. Condor 78:142

Stiles FG (1995) Intraspecific and interspecific variation in moult patterns of some tropical hummingbirds. Auk 112:118-132

Thomas ALR (1993) On the aerodynamics of birds' tails. Phil Trans R Soc Lond B 340:361-380

Tobalske BW (2007) Biomechanics of bird flight. J Exp Biol 210:3135-3146

Usherwood JR, Hedrick TL, McGowan CP, Biewener AA (2005) Dynamic pressure maps for wings and tails of pigeons in slow, flapping flight, and their energetic implications. J Exp Biol 208:355-369

Walker JA (1998) Estimating velocities and accelerations of animal locomotion: a simulation experiment comparing numerical differentiation algorithms. J Exp Biol 201:981-995

Warrick DR, Dial KP (1998) Kinematic, aerodynamic and anatomical mechanisms in the slow, maneuvering flight of pigeons. J Exp Biol 201:655-672

Warrick DR, Dial KP, Biewener AA (1998) Asymmetrical force production in the maneuvering flight of pigeons. Auk 115:916-928

Warrick DR, Bundle MW, Dial KP (2002) Bird maneuvering flight: blurred bodies, clear heads. Int Comp Biol 42:141-148

Woltring HJ (1985) On optimal smoothing and derivative estimation from noisy displacement data in biomechanics. Hum Mov Sci $4: 229-245$ 